\title{
RESENHAS
}

REVIEWS

\section{ÉTICA: DIREITO, MORAL E RELIGIÃO NO MUNDO MODERNO}

\author{
Fábio Konder Comparato \\ Companhia das Letras, São Paulo, 2006
}

\section{Wilson Ricardo Buquetti Pirotta ${ }^{(*)}$}

O livro Ética: direito, moral e religião no mundo moderno, do Professor Fábio Konder Comparato vem ao encontro da crescente necessidade de discussão sobre os dilemas éticos enfrentados na área da saúde e, no caso específico, pelos juristas que se dedicam aos estudos nessa área. Os conflitos entre interesses individuais e coletivos, entre autonomia privada e normas de ordem pública, as antinomias recorrentes nas diversas abordagens do Direito em relação à área da saúde, trazem de forma contínua para o centro da discussão a dimensão ética presente em cada uma das situações específicas. Fábio Konder Comparato é jurista doutorado pela Universidade de Paris, professor titular da Faculdade de Direito da Universidade de São Paulo (USP), presidente da Comissão de Defesa da República e da Democracia do Conselho Federal da Ordem dos Advogados do Brasil (OAB) e advogado de acusação no impeachment do ex-presidente Fernando Collor de Mello. Comparato tem se dedicado nos últimos anos a pesquisar e lecionar sobre direitos humanos e política, após profícua carreira na área do Direito Comercial e empresarial.

Comparato inicia seu livro sobre ética afirmando ser a busca da felicidade, "recompensa de um esforço constante e bem orientado" (p. 17), o que há de mais valioso na vida dos indivíduos e dos povos. Para o autor, é de

(*) Juiz do Trabalho Substituto do Tribunal Regional do Trabalho da Segunda Região, Mestrando em Direito pela Faculdade de Direito da Universidade de São Paulo. E-mail: <wpirotta@ hotmail.com>. 
suprema importância a investigação sobre o que é bom ou sobre o que é mau para se alcançar a felicidade. Não obstante, os termos ética e moral tenham sido freqüentemente utilizados de forma contrastante e por vezes antagônica nas diversas escolas filosóficas ao longo da história, tal distinção não se verifica no livro. Na obra de Comparato, o sentido dado à palavra ética "é bem largo: ela abrange o conjunto dos sistemas de dever-ser que formam, hoje, os campos distintos - e, na maioria das vezes, largamente contraditórios - da religião, da moral e do direito". O autor esclarece que um dos motivos condutores do livro consiste justamente na demonstração de que no mundo antigo era impossível distinguir ou opor essas três "esferas de regulação do comportamento humano", ao contrário do que veio a ocorrer na era moderna. (p. 18)

A história da filosofia traz inúmeros exemplos de termos e expressões a que são atribuídos significados próprios dentro de determinado período ou escola. Ainda que tais termos e expressões sejam utilizados de forma não técnica na língua corrente, como se dá com o termo ética, seu estudo como revelador de um dado pensamento filosófico ou período da história deve buscar verificar a especificidade com que são utilizados, analisando o percurso do conceito, sua permanência ou mutação ao longo do tempo. No livro, Comparato observa as diferentes concepções de ética ocorrentes ao longo da história, nas diversas escolas filosóficas por que passa, mas entende haver um conteúdo comum ao conceito que permanece ao longo do tempo.

Conforme seu autor, a exposição do livro segue duplo método: estrutural e histórico, dividindo-se em três partes. Na primeira parte, busca analisar "as características essenciais da vida ética no mundo antigo e os principais fatores responsáveis por sua transformação, de início no Ocidente e depois em todas as demais civilizações: a filosofia e o monoteísmo" A segunda parte é dedicada pelo autor a "refletir sobre o grande conflito ideológico, irrompido na Europa a partir do século XVI e prolongado até o século passado, conflito que moldou fundamente a mentalidade moderna". A última parte da obra "representa um esforço de construção das bases teóricas e institucionais de instauração de uma nova ética para a humanidade, agora que ela se transforma em sujeito unitário da História”. (p. 46).

De pronto, cumpre salientar que a opção pela utilização de dois métodos usualmente opostos no âmbito da pesquisa em ciências humanas deixa suas marcas no trabalho. O método histórico não se confunde com o estudo diacrônico do sistema sob inspeção, previsto pelo estruturalismo. Ao contrário, o estruturalismo afirma o primado da concepção transversal, que toma a realidade como um sistema relativamente constante e uniforme de relações, ao passo que o método histórico enfatiza justamente a concepção 
longitudinal da sociedade, interpretando-a em termos de desenvolvimento e progresso. Embora o autor tenha buscado refletir sobre as estruturas que determinam a concepção da ética nos diversos períodos da história da humanidade, termina por prevalecer, no livro, o método histórico, com a análise das constâncias e das transformações das relações sociais, políticas e jurídicas ao longo do tempo, bem como da concepção de ética em cada período da história. A prevalência do método histórico pode ser constatada em diversas passagens da obra, como, por exemplo, a passagem em que 0 autor afirma que "a evolução histórica aponta para a progressiva constituição de uma ordem jurídica superior, fundada nos mesmos valores de respeito integral à dignidade humana, ordem que é o sistema mundial de direitos humanos ..." (p. 361), trecho do qual também se infere a presença de forte tendência teleológica na concepção da obra e do traço marcante do projeto moderno, orientado pela busca de um modelo explicativo de validade universal. A passagem transcrita traz, ainda, uma das teses centrais do livro, que será retomada nas conclusões.

A importância associada aos personagens históricos também revela a menor relevância atribuída ao estruturalismo na concepção da obra. Comparato explica que, na segunda parte de sua obra, "não se trata (...) de uma exposição abstrata de teorias e sistemas de pensamento, mas de uma reflexão compreensiva, não apenas sobre idéias, mas também sobre modelos pessoais de vida (como os de São Francisco de Assis e de Gandhi) que influenciaram decisivamente a evolução histórica" (p. 46).

O mesmo sincretismo metodológico enunciado acima pode ser encontrado quando o autor trata dos referenciais teóricos de que pretende utilizar-se ao longo do trabalho. Diz ele que se encontra ultrapassada a organização em escolas mutuamente excludentes de três formas de interpretação da vida social, a saber, a idealista, a realista e a materialista. Propõe, ao contrário, a visão integradora das sociedades e das civilizações, uma visão holística sobre o mundo e a realidade, que não despreza nenhuma dessas concepções, mas tampouco eleva qualquer delas a centro da interpretação dos fatos. A exemplo do que foi dito acima quanto à contraposição do método histórico ao estrutural, as análises idealista e materialista são de difícil coexistência e, apesar da simpatia ao pensamento marxista revelada pelo autor, acaba por preponderar na obra uma abordagem mais próxima ao idealismo.

O eixo central do trabalho de Comparato desenvolve-se sobre a inspeção das transformações que levaram à modificação dos elementos essenciais da vida ética do mundo antigo para o mundo moderno e que desembocam na crise axiológica atual, em que o ser humano encontra-se diante de uma escolha dramática, da qual depende a própria continuidade de sua existência. 
Para o autor, no mundo antigo tudo era decidido pela religião, que não se distinguia da moral e do direito. A tradição, nesse sistema, era a autoridade máxima para a avaliação dos comportamentos humanos. O novo era visto com desconfiança. O indivíduo era absorvido pelo grupo social. Essa situação teria perdurado por milênios e encontrado um ponto de modificação a partir do período que Comparato, com Jaspers, denomina axial, entre os séculos VIII e II a. C., quando o surgimento da fé monoteísta e o saber filosófico fundado na razão produziram uma excepcional transformação nas idéias e instituições humanas, fazendo surgir a concepção da religião universal e, simultaneamente, a crítica racional dos preceitos éticos antigos.

$\mathrm{Na}$ era moderna, as transformações advindas do período axial atingem sua culminância, com a afirmação do indivíduo sobre o grupo social, o desenvolvimento das ciências e a disjunção entre os elementos componentes do mundo do dever-ser, quais sejam, a ética, a religião e o direito. Destaca-se o predomínio do Direito e sua consagração como direito estatal, relegando a ética e a religião ao âmbito dos assuntos privados. Ao contrário do que ocorria no mundo antigo, em que a tradição era tida por autoridade máxima e o novo era visto com desconfiança, o mundo moderno atribui papel central ao novo, tomando-o por valor em si mesmo.

Dois conceitos centrais permeiam o texto de Comparato e acompanham a obra desde seu início até sua conclusão: o conceito de dignidade da pessoa humana e o conceito de bem comum.

O termo dignidade associado à humanidade e na forma da proposição de um princípio da dignidade humana é introduzido na filosofia por Kant, mais propriamente na Fundamentação da Metafísica dos Costumes. Para Kant, o princípio da dignidade humana assume a forma de imperativo categórico, segundo o qual o ser racional deve agir de tal forma a tratar a humanidade em sua própria pessoa e nas demais como um fim em si e nunca como um meio. Os seres racionais, segundo Kant, estão sujeitos à lei em virtude da qual cada um deles nunca deve tratar-se a si mesmo e aos outros como puros meios para a obtenção de dado fim, mas sempre como fins em si. O tratamento como fim em si mesmo deve ser dirigido pelo ser racional a si mesmo e a todos os outros seres racionais de forma simultânea.

Diz Kant que no reino dos fins tudo tem um preço ou uma dignidade. Para ele, reino significa a união sistemática de diversos seres racionais por meio de leis comuns. Reino dos fins seria o conjunto de todos os fins, quais sejam, os seres racionais, que são fins em si mesmos, e os fins próprios que cada qual pode propor-se. O que tem um preço pode ser substituído por algo equivalente, mas o que está acima de qualquer preço e não admite equivalente é dito que possui dignidade. Os seres racionais, por serem fins em si 
mesmos e nunca meio, não possuem apenas um valor relativo, isto é, um preço, mas sim um valor intrínseco, ou seja, uma dignidade.

O conceito de dignidade da pessoa humana adquiriu papel central nas discussões sobre direitos humanos ao longo do século $X X$, sobretudo frente ao genocídio praticado pelos regimes totalitários contra diversos povos. $\mathrm{Na}$ Declaração Universal dos Direitos Humanos de 1948, reconhece-se explicitamente que a dignidade inerente a todos os membros da família humana e seus direitos iguais e inalienáveis é o fundamento da liberdade, da justiça e da paz no mundo. As diversas constituições promulgadas após a Segunda Guerra foram assimilando em seus textos o princípio de respeito à dignidade da pessoa humana como fundamento do estado de direito.

Embora o conceito de dignidade da pessoa humana apareça inúmeras vezes ao longo do livro, na Parte III, Capítulo II, Comparato dedica uma seção à análise do conceito e de sua situação de supremo modelo ético, bem como dedica outra seção para análise do fundamento da dignidade humana. Perquirindo da história o conceito de pessoa, o autor chega à separação medieval entre persona personalis e persona idealis e afirma que "Essa teoria medieval nos permite compreender em sua plenitude o contraste entre a dignidade transcendente da pessoa humana, enquanto supremo modelo da vida ética, e a individualidade pessoal de cada ser humano, com todas as suas limitações e deficiências. O paradigma da pessoa humana reúne em si a totalidade dos valores; ela é o supremo critério axiológico a orientar a vida de cada um de nós" (p. 481).

O fundamento da dignidade humana é buscado pelo autor a partir de três perspectivas não excludentes, a religiosa, a filosófica e a científica. Em consonância com a tese desenvolvida na primeira parte do livro, o autor realça a importância do monoteísmo na afirmação da dignidade da pessoa humana. No âmbito da filosofia o autor liga o reconhecimento da dignidade da pessoa humana à condição de ser racional e à consciência individual e coletiva do ser humano. Sob um prisma científico, entende Comparato que a ciência apresenta a espécie humana como o ápice do processo evolutivo.

Quanto ao conceito de bem comum, a concepção de que a reunião dos indivíduos em grupos e dos grupos em estruturas mais amplas coloca a questão da contraposição entre os interesses particulares e os interesses gerais do todo. Esse assunto é recorrente na República, de Platão, na Política e na Ética a Nicômaco, de Aristóteles. A discussão sobre a especificidade da vida em comunidade passa necessariamente pela perquirição sobre o que constitui o bem afeito a toda a comunidade, seja ela a cidade, a república, a nação etc., valorando-o e sopesando-o em consideração ao que se entende por bem particular. A busca da harmonização entre os interesses 
particulares e os interesses gerais do agrupamento político ou a pesquisa sobre a ordem de preferência entre tais classes de interesses são assuntos presentes nos textos dos filósofos que se dedicaram a pensar sobre a política. Trata-se da discussão sobre o argumento de que sem uma base cultural e de interesses comuns, com alguma coincidência quanto aos valores buscados em comunidade política, a sociedade arrisca-se a se desintegrar.

A expressão bem comum designando um dado conceito próprio da filosofia política, porém, é típica do pensamento político católico, configurando-se de forma nítida na escolástica, em suas várias manifestações, embora já presente de forma bastante sensível nos escritos dos retóricos da Ars Dictaminis - escola medieval de estudos sobre a retórica. $\mathrm{Na}$ concepção escolástica, o bem comum apresenta-se simultaneamente como o princípio edificador da sociedade humana e o fim para o qual ela deve orientar-se do ponto de vista natural e temporal. $O$ bem comum busca a felicidade natural, o que o torna o valor político por excelência, sempre, porém, subordinado à moral. Nessa concepção, não se confunde o bem comum com o bem público: o bem público pertence a todos por estarem unidos, ou seja, permanece tal bem externo a cada indivíduo, ao passo que o bem comum é dos indivíduos como membros de uma comunidade política. Não se concebe o bem comum como a mera somatória dos bens individuais, mas possuidor de uma própria essência.

As ligações do conceito de bem comum com o pensamento político católico fizeram com que muitos autores recusassem-no para as discussões dos problemas próprios dos estados laicos contemporâneos. Comparato, porém, entende que o conceito de bem comum não se esgotou como fonte de inspiração e reflexão sobre a filosofia política e sobre o desenvolvimento das relações políticas no seio do Estado moderno. Relaciona ele o conceito de bem comum à essência do regime republicano. Diz: "A essência do regime político republicano encontra-se na distinção entre o interesse próprio de cada um em particular e o bem comum de todos, com a exigência de que este se sobreponha sempre àquele. Os indivíduos podem viver isoladamente em função de seu interesse particular. É a idéia expressa pelos pensadores políticos dos séculos XVII e XVIII, com a fórmula do 'estado de natureza'. Mas a convivência política exige o respeito superior ao interesse comum de todos os membros do grupo social ('o estado civil')." (p. 617-618) Assim, a supremacia do respeito ao bem comum sobre o interesse particular é a própria natureza do regime republicano. Observa o autor que o "contrário da comunidade republicana é o regime tirânico, em que tudo e todos dependem da vontade arbitrária daquele que monopoliza o poder". (p. 619) 0 arbítrio, forma de inverter a proposição sobre a prevalência do bem comum 
no regime republicano, representa uma superposição de interesses particulares e, retomando o sentido atribuído ao termo pelos pensadores políticos do Renascimento e seus sucessores imediatos, uma forma de corrupção.

Para Comparato, as instituições sociais devem ser moldadas com base no princípio republicano. Entende ele que são quatro as instituições basilares a serem consideradas, quais sejam: a supremacia dos direitos humanos, respeitados em sua integralidade; a abolição dos privilégios particulares, seja de pessoas ou de corporações; a vedação à apropriação privada dos bens comuns; e a publicidade integral dos atos oficiais (p. 622).

O capítulo reservado à conclusão da obra traz por título "O sentido ético da vida humana". Nele, o autor, partindo da análise de mitos, observa que a "convivência harmoniosa de indivíduos e povos, embora destinados todos um dia a desaparecer, é sempre preferível à busca insensata da imortalidade" (p. 691). Afirma também que a vida para o ser humano ultrapassa o plano de um mero existir biológico, sendo um eterno escolher caminhos em busca da felicidade, que se revela no viver para o bem, donde conclui que "o verdadeiro sentido da vida humana é manifestamente ético". (p. 695)

No que tange à história e à evolução das civilizações, nelas também vê Comparato um sentido ético. Retomando o percurso desenvolvido no livro, o autor conclui que, no mundo contemporâneo, "A religião e a moral foram confinadas à condição de meros costumes privados, e submetidas ao direito, reconhecido doravante como a manifestação de vontade própria do soberano político, imposta coercitivamente aos povos. No entanto, por trás das divergências ideológicas, da intensificação dos choques culturais e da mundialização dos conflitos armados do século XX, é possível enxergar, atuando em profundidade desde $o$ início do mundo moderno, dois movimentos antagônicos, de cujo embate depende hoje o futuro da humanidade: o capitalismo e a construção do sistema mundial dos direitos humanos". (p. 698) O Professor Comparato opta por afirmar a construção do sistema mundial de direitos humanos como a única saída possível para a própria continuidade da existência da humanidade, frente à encruzilhada entre consumir o globo terrestre e seus ocupantes até o seu esgotamento e a preservação da dignidade da pessoa humana, com base no bem comum.

A obra ora apresentada está em consonância com as linhas contemporâneas de pensamento que pugnam pelo desenvolvimento do sistema mundial de direitos humanos como a única saída viável para a crise atual da humanidade. Representa uma retomada importante dos estudos sobre ética, sobretudo no campo do direito, estudos relegados a segundo plano durante muito tempo. 
Trata-se de uma obra de fôlego, com dimensões enciclopédicas, na qual o autor não tem medo de dizer o que pensa, mesmo sem o respaldo do que é considerado na academia como metodologicamente preciso. Tal disposição remonta à tradição filosófica humanista, embora o trabalho possua a característica própria do projeto moderno de buscar a exaustão de um assunto e um modelo de validade universal.

O livro interessa a todo o tipo de leitor; mas, é especialmente indicado para os estudiosos das áreas do Direito em que a ética é presença constante e fundamental, como os estudos do direito à saúde e os estudos no campo dos direitos humanos. 